Chintya Melinda, Riris Loisa, Lusia Savitri Setyo Utami: Pengaruh Strategi Pesan Iklan Imagine Your Korea Dalam Membangun Brand Awareness

\title{
Pengaruh Strategi Pesan Iklan Imagine Your Korea Dalam Membangun Brand Awareness
}

\author{
Chintya Melinda, Riris Loisa, Lusia Savitri Setyo Utami \\ chintyam31@gmail.com \\ Fakultas Ilmu Komunikasi Universitas Tarumanagara
}

\begin{abstract}
As the result of developing era, mass media is also developing significantly, in nowadays, mass media has more structure and function. Likewise advertisement, advertisement nowadays is developing rapidly using the development of technology, we called it digital media. So, the kind of media that we chose has to be suitable with the product and customer segment of the product. In this research, writer analysed does strategical message of Imagine Your Korea advartisment in Yourube could appeal Indonesian People to go to Korea and explore the country. The Strategical message from that advertisement packed with so many kind of approach, so the strategical message could influenced a Brand Awareness. The writer used quantitative approach to do and finished this research.The results of quantitative approach that the writer used were both variable affected each other, with $t$ test value $=7,926$. The affect was pretty significant between both variable, it's shown when 0,000<0,05. And as the result of statistic regression, the writer could conclude that strategical message affected brand awareness with 46,4\%.
\end{abstract}

Keywords : advertising, korea, message advertising strategy , brand awareness.

\begin{abstract}
Abstrak
Seiring perkembangan zaman, media massa ikut berkembang dengan pesat sehingga menjadi lebih beragam, baik dalam bentuk maupun fungsi. Begitu juga pada media iklan yang kini sudah mulai merambah memanfaatkan perkembangan elektronik, atau biasa dikenal dengan media digital. Maka dari itu, pemilihan media harus disesuaikan dengan produk dan target sasaran produk tersebut, karena penempatan media memiliki pengaruh yang besar terhadap keberhasilan iklan. Pada penelitian ini penulis menganalisa apakah strategi pesan iklan Imagine Your Korea melalui media youtube di Indonesia dapat menarik masyarakat Indonesia untuk berpariwisata dan menjelajahi negara Korea. Strategi pesan dari iklan tersebut dikemas dengan berbagai pendekatan sehingga memunculkan suatu Brand awareness yang telah dibahas sebelumnya. Penulis menggunakan pendekatan metode kuantitatif untuk melakukan penelitian hingga mengolah dan memperoleh hasil yang diinginkan oleh penulis. Berdasarkan hasil penelitian yang telah penulis lakukan terhadap variabel-variabel dalam penelitian dapat disimpulkan bahwa terdapat pengaruh yang terjadi antara kedua variabel dengan angka uji $\mathrm{t}=7,926$. Pengaruh yang terjadi juga menunjukkan pengaruh yang signifikan dengan jumlah tingkat signifikasi $=0,000<0,05$. Dengan kata lain, Ha diterima seluruhnya, dan Ho ditolak. Berdasarkan perhitungan regresi dari data penelitian, strategi iklan $46,4 \%$
\end{abstract}


mempengaruhi brand awareness iklan Imagine Your Korea. Sedangkan sisanya, yaitu sebesar 53,6\% dipengaruhi oleh faktor-faktor lain.

Kata kunci : iklan, korea, strategi pesan iklan, brand awareness

\section{Pendahuluan}

Hallyu atau Korean Wave adalah istilah yang diberikan untuk tersebarnya budaya pop Korea secara global di berbagai negara di dunia. Umumnya Hallyu memicu banyak orang untuk mempelajari Bahasa Korea dan kebudayaan Korea. Korean wave mengacu pada penyebaran budaya Korea Selatan di seluruh dunia atau kecintaan terhadap eksport budaya Korea Selatan. Eksport kebudayaan Korea Selatan inipun tersebar ke seluruh penjuru dunia melalui media massa, internet, maupun televisi.

Seiring perkembangan zaman, media massa pun ikut berkembang dengan pesat sehingga menjadi lebih beragam, baik dalam bentuk maupun fungsi. Media massa umumnya dimanfaatkan untuk menyebarluaskan informasi, berita, dan tidak jarang media massa digunakan untuk pembentukan opini. Banyak pihak juga yang memanfaatkan media massa untuk mengiklankan produk yang mereka jual. Salah satu contoh media massa yang penulis katakan berkembang dengan cepat adalah media iklan Iklan adalah bentuk komunikasi berbayar yang menggunakan media massa dan media interaktif untuk menjangkau audiensi yang luas dalam rangka menghubungkan sponsor yang jelas dengan pembeli dan memberikan informasi tentang produk (Moriarty, 2011: 9). Media yang digunakan untuk beriklan sangat beragam, dapat melalui media cetak, media elektronik, media digital dan bahkan media bergerak. Maka dari itulah, pemilihan media harus disesuaikan dengan produk dan target sasaran produk tersebut, karena penempatan media memiliki pengaruh yang besar terhadap keberhasilan iklan.

Konsumen memiliki karakter dan latar belakang masing-masing sehingga untuk menarik konsumen, strategi pesan iklan harus memenuhi kriteria target pasar. Pesan iklan harus dikemas dan disusun menggunakan strategi yang tepat agar konsumen tertarik untuk mempelajari dan melihat konten mengenai produk tertentu. Strategi pesan membantu dalam menentukan bagaimana cara menggunakan konten untuk memenuhi sebuah tujuan persuasif, dan memenuhi kebutuhan pengguna, serta menjadi sebuah tolakukur untuk mengukur keberhasilan sebuah konten (Halvorson, 2010).

Keberhasilan paling dasar iklan dapat dilihat dari kesadaran masyarakat terhadap merek atau biasa dikenal dengan istilah Brand Awareness. Brand awareness adalah kemampuan sebuah merek untuk muncul dalam benak konsumen ketika mereka sedang memikirkan kategori produk tertentu dan seberapa mudahnya nama tersebut muncul (Shimp dalam Wahid, 2017: 4). Definisi lainnya menyatakan bahwa brand awareness sebagai kesanggupan seorang calon pembeli untuk mengenali, mengingat kembali suatu merek sebagai bagian dari suatu kategori produk tertentu (Durianto dalam Wahid, 2017: 4).

Brand awareness sangat penting bagi merek karena tidak hanya menarik konsumen untuk membeli pertama kalinya, brand awareness juga dapat menjadikan konsumen untuk menjadi konsumen tetap. Brand awareness membantu melekatkan merek terhadap gaya hidup dan daya ingat masyarakat, karena masyarakat lebih memilih untuk membeli barang atau menggunakan jasa dari merek terpercaya dan merek yang 
Chintya Melinda, Riris Loisa, Lusia Savitri Setyo Utami: Pengaruh Strategi Pesan Iklan Imagine Your Korea Dalam Membangun Brand Awareness

tidak asing lagi. Jika kepuasan konsumen dapat terpenuhi oleh merek tertentu, pada umumnya konsumen cenderung akan mempromosikan merek tersebut kepada lingkungan sekitarnya.

Kembali ke pesat nya perkembangan Korean Wave yang sejajar dengan media iklan di berbagai negara di seluruh dunia, dan salah satu nya di Indonesia, penulis ingin membahas bagaimana negara Korea memiliki peluang untuk mengenalkan kebudayaan, gaya hidup dan khususnya pariwisata negara Korea terhadap masyarakat Indonesia. Salah satu peluang negara Korea tersebut yang terlihat jelas adalah keberadaan Korea Tourism Organization (KTO) di Indonesia, dimana organisasi tersebut memanfaatkan dunia digital untuk mengenalkan serta melakukan promosi negara Korea. Singkatnya, Penulis di sini ingin membahas bagaimana pengaruh media iklan Imagine Your Korea terhadap pengenalan dan kemajuan dari pariwisata negara Korea tersebut.

Penulis ingin menganalisa apakah strategi pesan iklan Imagine Your Korea melalui media youtube di Indonesia dapat menarik masyarakat Indonesia untuk berpariwisata dan menjelajahi negara Korea. Strategi pesan dari iklan tersebut dikemas dengan berbagai pendekatan sehingga memunculkan suatu Brand awareness yang telah dibahas sebelumnya.

Penelitian ini diharapkan mampu memberikan pengetahuan secara akademis dan praktis. Secara akademis penelitian ini bermanfaat untuk :

a. Manfaat dari penelitian ini dalam segi teori adalah mendapatkan informasi dan defisini dari strategi pesan iklan dan definisi brand awareness. Penelitian ini diharapkan dapat melihat hubungan sebab-akibat atau pengaruh dari kedua elemen tersebut. Penelitian ini juga diharapkan dapat membantu para pembaca untuk melihat detail-detail yang terkandung di dalam strategi pesan iklan sekaligus mendefinisikan kegunaan masing-masing elemen tersebut sehingga dapat membentuk adanya brand awareness.

b. Peneliti berharap penelitian ini dapat memberikan informasi dan wawasan kepada para peneliti lain khususnya dalam bidang periklanan yang menyangkut strategi pesan iklan dan kegunaannya.

c. Peneliti juga berharap penelitian ini dapat memberikan informasi dan wawasan kepada para peneliti lain menyangkut brand awareness beserta hubungannya dengan strategi pesan iklan

Sedangkan secara praktis

a. Melalui penelitian ini, penulis berharap dapat memberikan manfaat juga saran dan masukan bagi pihak yang terkait dalam menentukan strategi pesan iklan. Penulis berharap dengan penelitian ini juga dapat mempermudah orang periklanan untuk membuat strategi pesan iklan yang dapat membentuk brand awareness.

\section{Metode Penelitian}

Penelitian yang dilakukan penulis berupa penelitian kuantitatif yang menjawab tujuan penelitian dengan cara menentukan dan menganalisa hubungan dari masingmasing variable, dimana masing-masing variabel memiliki nilai nya masing-masing. Menurut Creswell (2014:32) metode pendekatan kuantitatif juga menuntut adanya penggunaan angka, sehingga dapat dianalisa dengan prosedur-prosedur statistik. 
Data yang digunakan oleh peneliti pada penelitian "Strategi Pesan Iklan Imagine Your Korea" adalah data yang berjenis primer dan sekunder. Dalam penelitian ini, penulis secara langsung mencari data dengan cara melakukan studi kasus dan kuisioner. Berikut adalah pembahasannya:

a. Metode Studi Dokumen

Menurut Sugiyono (2013:204) teknik studi dokumen adalah Teknik dimana peneliti mempelajari dokumen yang bisa berupa tulisan, gambar, atau karya-karya lain yang telah diabadikan sebelumnya. Pada penelitian ini, penulis menggunakan Teknik studi dokumen ini dengan cara membaca buku, jurnal, maupun penelitian-penelitian terdahulu yang berhubungan dengan iklan, strategi pesan iklan, dan juga tentu saja Brand awareness. Data yang akan diperoleh dari metode studi dokumen di sini berupa pengetahuan (definisi dan element-element) yang ada pada sebuah strategi pesan iklan dan juga brand awareness.

b. Metode Kuisioner

Menurut Suroyo Anwar (2009:168), kuisioner adalah sejumlah pertanyaan tertulis tentang data faktual atau opini yang berkaitan dengan diri responden, yang hasilnya dianggap sebagai informasi yang perlu diketahui. Pada penelitian ini, penulis sebagai peneliti akan melakukan metode kuisioner orang-orang di sekitar penulis yang penulis anggap untuk memenuhi karakteristik sebagai sampel. Hal ini dilakukan guna untuk memperoleh opini sekaligus pengetahuan yang lebih tentang bagaimana opinisi masyarakat terhadapat pengaruh strategi pesan iklan imagine Your Korea terhadap brand awareness mereka.

Teknik pengolahan data yang penulis gunakan disebut dengan Uji t, yang dilakukan menggunakan bantuan program SPSS 22. Uji t dalam penelitian ini digunakan untuk menentukan apakah hipotesis alternatif diterima atau belum dapat diterima.

$$
\mathrm{t}_{\text {hitung }}=\frac{\sqrt{\mathrm{n}-2}}{\sqrt{1-r^{2}}} \quad \text { (Sekaran:117) adalah sebagai berikut: }
$$

Dimana:

$\mathrm{t}=\mathrm{t}$ hitung

$\mathrm{r}=$ Perason Product Moment

$\mathrm{n}=$ Jumlah Sampel

Dasar pengambilan keputusan adalah sebagai berikut:

a. Jika $t_{\text {hitung }}<\mathrm{t}_{\text {tabel }}$ dan nilai Sig $>0,05$, maka Ho diterima dan Ha ditolak, artinya secara parsial variabel independen mempunyai pengaruh yang tidak signifikan terhadap variabel dependen.

b. Jika $t_{\text {hitung }}>t_{\text {tabeld }}$ dan nilai Sig $<0,05$, maka Ho ditolak dan Ha diterima, artinya secara parsial variabel independen mempunyai pengaruh yang signifikan terhadap variabel dependen. 
Chintya Melinda, Riris Loisa, Lusia Savitri Setyo Utami: Pengaruh Strategi Pesan Iklan Imagine Your Korea Dalam Membangun Brand Awareness

\section{Hasil Temuan dan Diskusi}

Setelah melakukan metode penelitian di atas, berikut adalah hasil-hasil yang diperoleh :

Gambaran Umum Iklan Imagine Your Korea

Setiap tahun nya, Korean Tourism Organization meluncurkan iklan pariwisata negara Korea melalui media Youtube. Di tahun 2018 iklan pariwisata dengan tema "Imagine Your Korea" tersebut memilih EXO sebagai celebrity ambassador nya, karena melihat kesuksesan dan banyaknya fans boyband tersebut. Menurut Korea Foundation of Cultural Exchange, Korean Wave merupakan daya tarik yang menumbuhkan keinginan khalayak untuk mengunjungi Korea (Lee, 2013). Oleh karena alasan tersebut, dapat dilihat bahwa unsur Korean Wave seringkali dihadirkan di iklan pariwisata Korea.

Hasil Kuisioner Strategi Pesan:

Jalan Cerita Iklan Imagine Your Korea Mampu Menjelaskan Tentang KeunggulanKeunggulan Yang Menjadikan Korea Sebagai Destinasi Wisata

\begin{tabular}{clrr}
\hline & Frequency & \multicolumn{1}{r}{ Percent } \\
\hline Valid & 3 & $3 \%$ \\
& Sangat Tidak Setuju & 14 & $14 \%$ \\
Tidak Setuju & 14 & $14 \%$ \\
Netral & 51 & $51 \%$ \\
Setuju & 18 & $18 \%$ \\
Sangat Setuju & 100 & $100 \%$ \\
Total
\end{tabular}

Sumber: Pengolahan Data SPSS Item Kuisioner Variabel X Nomor 4

Iklan Imagine Your Korea Meningkatkan Keinginan Saya Untuk Berkunjung ke

\begin{tabular}{llrr}
\multicolumn{3}{c}{ Korea Selatan } \\
\hline & Frequency & Percent \\
\hline Valid & 4 & 4.0 \\
Sangat Tidak Setuju & 14 & 14.0 \\
Tidak Setuju & 32 & 32.0 \\
Netral & 43 & 43.0 \\
Setuju & 7 & 7.0 \\
Sangat Setuju & 100 & 100.0 \\
Total &
\end{tabular}

Sumber: Pengolahan Data SPSS Item Kuisioner Variabel X Nomor 13

Hasil Kuisioner Brand Awareness:

Ketika Melihat Iklan Imagine Your Korea, Saya Menjadi Tertarik Mengunjungi

\begin{tabular}{clrr}
\multicolumn{3}{c}{ Korea Selatan } \\
\hline & \multicolumn{1}{c}{ Frequency } & \multicolumn{1}{c}{ Percent } \\
\hline Valid & 5 & 5.0 \\
Sangat Tidak Setuju & 13 & 13.0 \\
Tidak Setuju & 18 & 18.0 \\
Netral & 57 & 57.0 \\
Setuju & 7 & 7.0 \\
Sangat Setuju & 100 & 100.0 \\
Total &
\end{tabular}

Sumber: Pengolahan Data SPSS Item Kuisioner Variabel Y Nomor 4 
Selalu Mengingat Iklan Imagine Your Korea Ketika Saya Memiliki Keinginan Untuk Berlibur

\begin{tabular}{llrrr}
\hline & Frequency & Percent & Valid Percent & \multicolumn{2}{c}{ Cumulative } \\
Percent
\end{tabular}

Sumber: Pengolahan Data SPSS Item Kuisioner Variabel Y Nomor 6

Analisis Data:

Setelah melakukan uji reliabilitas, uji analisis t, uji regresi linear sederhana, pada datadata yang telah terkumpul sebelumnya, berikut adalah hasil yang dapat penulis simpulkan :

a. Uji t

\begin{tabular}{|c|c|c|c|c|c|c|}
\hline & \multicolumn{6}{|c|}{ Hasil Uji t } \\
\hline & Model & Unstanda & Joefficients & $\begin{array}{c}\text { Standardized } \\
\text { Coefficients }\end{array}$ & $\mathrm{t}$ & Sig. \\
\hline 1 & $\begin{array}{l}\text { (Constant) } \\
\text { Strategi Iklan }\end{array}$ & $\begin{array}{c}\mathrm{B} \\
15.821 \\
.519\end{array}$ & $\begin{array}{c}\text { Std. Error } \\
3.128 \\
.219 \\
\end{array}$ & $\begin{array}{l}\text { Beta } \\
.658 \\
\end{array}$ & $\begin{array}{c}21.170 \\
7.926 \\
\end{array}$ & $\begin{array}{l}.000 \\
.000\end{array}$ \\
\hline
\end{tabular}

Hasil uji t menunjukkan apakah variabel X (Strategi Iklan) memiliki pengaruh yang signifikan terhadap variabel Y (Brand Awareness). Pengujian tersebut dapat dilakukan dengan pembuktian sebagai berikut:

1) Ho: Sig $>\alpha$, tidak ada pengaruh antara Strategi Iklan (X) terhadap Brand Awareness (Y)

2) Ha: Sig $<\alpha$, terdapat pengaruh antara Strategi Iklan (X) terhadap Brand Awareness.

Berdasarkan hasil analisis data diketahui bahwa nilai $\mathrm{t}=7.926$ dan tingkat signifikasi $=0,000<0,05$. Karena nilai t lebih besar dari t tabel $(1,984)$ dan nilai $\mathrm{p}<$ 0,05, maka $\mathrm{H}_{\mathrm{o}}$ ditolak dan $\mathrm{H}_{\mathrm{a}}$ diterima, yang berarti terdapat pengaruh positif strategi iklan terhadap brand awareness. Dengan demikian semakin baik strategi iklan yang diterapkan maka brand awareness pada iklan Imagine Your Korea juga akan semakin baik, begitu juga sebaliknya semakin buruk strategi iklan yang diterapkan maka brand awareness pada iklan Imagine Your Korea juga akan semakin buruk.

Pengaruh Strategi Iklan terhadap Brand Awareness Imagine Your Korea:

Dari hasil data yang diteliti, dapat disimpulkan bahwa Hipotesis Altenatif $\left(\mathrm{H}_{\mathrm{a}}\right)$ yang telah diajukan sebelumnya yaitu terdapat pengaruh antara strategi iklan (X) terhadap brand awareness (Y) pada Iklan Imagine Your Korea dapat diterima seluruhnya. Lalu, setelah dilakukan pengujian hipotesis ditemukan bahwa hasil hitung $\mathrm{H}_{\mathrm{o}}$ ditolak sedangkan $\mathrm{H}_{\mathrm{a}}$ diterima, yaitu terdapat pengaruh yang terjadi antara kedua variabel.

Menurut Brian Suhermas (2009) strategi iklan memiliki pengaruh signifikan terhadap Kesadaran Merek (Brand awareness). Dinasty (2011) dalam penelitiannya yang berjudul Pengaruh Iklan Teh Botol Sosro terhadap Kesadaran Merek (Brand Awareness) Konsumen di Kota Padang. Penelitian tersebut menemukan bahwa daya tarik pesan, bintang iklan, gambar, warna, musik dan slogan iklan Teh Botol Sosro 
Chintya Melinda, Riris Loisa, Lusia Savitri Setyo Utami: Pengaruh Strategi Pesan Iklan Imagine Your Korea Dalam Membangun Brand Awareness

berpengaruh signifikan terhadap kesadaran merek (brand awareness) pada konsumen di kota padang.

\section{Simpulan}

Berdasarkan hasil penelitian yang telah penulis lakukan terhadap variabel-variabel dalam penelitian dapat disimpulkan bahwa:

1. Hipotesis Alternatif (Ha) yang telah diajukan sebelumnya dapat dibuktikan bahwa pengaruh antara Strategi Iklan terhadap brand awareness pada iklan Imagine Your Korea dapat diterima seluruhnya.

2. Pengajuan hipotesis ditemukan hasil perhitungan $\mathrm{H}_{\mathrm{o}}$ ditolak sedangka $\mathrm{H}_{\mathrm{a}}$ diterima, yaitu terdapat pengaruh yang terjadi antara kedua variabel dengan angka uji $\mathrm{t}=$ 7,926. Pengaruh yang terjadi juga menunjukkan pengaruh yang signifikan dengan jumlah tingkat signifikasi $=0,000<0,05$.

3. Berdasarkan perhitungan regresi dari data penelitian, strategi iklan 46,4\% mempengaruhi brand awareness iklan Imagine Your Korea. Sedangkan sisanya, yaitu sebesar 53,6\% dipengaruhi oleh faktor-faktor lain.

\section{Ucapan Terima Kasih}

Penulis mengucapkan terima kasih kepada pihak-pihak yang telah membantu dalam proses penelitian hingga selesai. Dari mulai pihak universitas, dosen pembimbing, orang tua, dan teman-teman seperjuangan.

\section{Daftar Pustaka}

Anwar, Sutoyo. (2009). Pemahaman Individu, Observasi, Checklist, Interviu, Kuesioner, dan sosiometri. Yogyakarta: Pustaka Pelajar.

Bungin, Burhan. (2005). Metode Penelitian Kuantitatif. Jakarta: Prenadamedia.

Dinasty. (2011). Pengaruh Iklan Teh Botol Sosro terhadap Kesadaran Merek (Brand Awareness) Konsumen di Kota Padang. Skripsi tidak diterbitkan. FE UNAND.

Moriarty, Sandra, Nancy Mitchell, dan William Wells. (2011). Advertising Edisi 8. Jakarta: Kencana Prenada Media Grup.

Sugiyono. (2012). Metode Penelitian Kuantitatif Kualitatif dan R\&D. Bandung: Alfabeta.

Buzz Korea. (2014). About Buzz, Korea. Retrieved April 13, 2015, from

iBuzz Korea: http://www.ibuzzkorea.com/about/aboutbuzz.html 